\title{
Prolonged Epileptiform Discharges Induced by Altered Group I Metabotropic Glutamate Receptor-Mediated Synaptic Responses in Hippocampal Slices of a Fragile X Mouse Model
}

\author{
Shih-Chieh Chuang, ${ }^{1}$ Wangfa Zhao, ${ }^{1}$ Robert Bauchwitz, ${ }^{2}$ Qijiang Yan, ${ }^{2}$ Riccardo Bianchi, ${ }^{1}$ and Robert K. S. Wong ${ }^{1}$ \\ ${ }^{1}$ Department of Physiology and Pharmacology, State University of New York Health Science Center at Brooklyn, Brooklyn, New York 11203, and \\ ${ }^{2}$ Department of Neurology, St. Luke's Roosevelt Institute for Health Sciences, Columbia University, New York, New York 10019
}

\begin{abstract}
Mutations in FMR1, which encodes the fragile X mental retardation protein (FMRP), are the cause of fragile X syndrome (FXS), an $\mathrm{X}$-linked mental retardation disorder. Inactivation of the mouse gene Fmr1 confers a number of FXS-like phenotypes including an enhanced susceptibility to epileptogenesis during development. We find that in a FXS mouse model, in which the function of FMRP is suppressed, synaptically released glutamate induced prolonged epileptiform discharges resulting from enhanced group I metabotropic glutamate receptor (mGluR)-mediated responses in hippocampal slices. The induction of the group I mGluR-mediated, prolonged epileptiform discharges was inhibited in preparations that were pretreated with inhibitors of ERK1/2 (extracellular signal-regulated kinase 1/2) phosphorylation or of mRNA translation, and their maintenance was suppressed by group I mGluR antagonists. The results suggest that FMRP plays a key role in the control of signaling at the recurrent glutamatergic synapses in the hippocampus. The absence of this control causes the synaptically activated group I mGluRs to elicit translation-dependent epileptogenic activities.
\end{abstract}

Key words: mGluR; epilepsy; FMRP; fragile X; synaptic plasticity; synchronization

\section{Introduction}

Fragile X syndrome (FXS) is the most common hereditary form of mental retardation. The syndrome is caused by a trinucleotide repeat (CGG) expansion that results in epigenetic silencing of the gene FMR1 and prevents the expression of the encoded protein, the fragile X mental retardation protein (FMRP) (O'Donnell and Warren, 2002). FMRP is an RNA-binding protein and may function as a negative regulator of protein synthesis at the translation level (Caudy et al., 2002; Ishizuka et al., 2002; Jin et al., 2004; Aschrafi et al., 2005; Qin et al., 2005) (but see Todd et al., 2003).

In the CNS, synaptically activated mRNA translation is reported to be involved in several forms of synaptic plasticity (Steward and Schuman, 2003; Kelleher et al., 2004; Klann and Dever, 2004). In particular, translational processes appear to underlie group I metabotropic glutamate receptor (mGluR)-mediated synaptic plasticity (Huber et al., 2000; Raymond et al., 2000; Karachot et al., 2001; Hou and Klann, 2004; Shin et al., 2004; Aschrafi et al., 2005). FMRP may be coupled to group I mGluR activities (Weiler et al., 1997) and may mediate synaptic plasticity via its action on mRNA translation. In a fragile X mouse model, in

\footnotetext{
Received May 3, 2005; revised July 7, 2005; accepted July 28, 2005.

This work was supported by FRAXA Research Foundation and National Institutes of Health Grant NS35481.

Correspondence should be addressed to either Riccardo Bianchi or Robert K. S. Wong, Department of Physiology and Pharmacology, State University of New York Downstate Medical Center, 450 Clarkson Avenue, Brooklyn, NY 11203. E-mail: rbianchi@downstate.edu or bwong@downstate.edu.

DOI:10.1523/JNEUROSCI.1777-05.2005

Copyright $\odot 2005$ Society for Neuroscience $\quad$ 0270-6474/05/258048-08\$15.00/0
}

which FMRP is functionally absent, the mRNA translationdependent long-term depression induced by group I mGluR stimulation is enhanced (Huber et al., 2002).

Epileptogenesis is another form of plasticity elicited by group I mGluR activation. In hippocampal slices, transient application of the group I mGluR agonist ( $S$ )-3,5-dihydroxyphenylglycine (DHPG) elicited persistent prolonged ( $>2 \mathrm{~s}$ ) synchronized discharges of the CA3 population (Taylor et al., 1995; Zhao et al., 2004). These prolonged synchronized discharges resemble ictal discharges in epilepsy and have been used as a model to study epileptogenesis (Wong et al., 2004). Three properties of the group I mGluR-dependent ictal-like discharges make them particularly interesting as an epileptogenesis model: (1) their induction is dependent on mRNA translation (Merlin et al., 1998); (2) once induced by the agonist, they are maintained for hours even after the agonist washout (Merlin and Wong, 1997); (3) expression of the prolonged synchronized discharges is reversibly suppressed by group I mGluR antagonists (Merlin and Wong, 1997). The usefulness of the model has been limited in that epileptogenic activity can be elicited only by an agonist, DHPG, and not via synaptic activation of group I mGluRs (Lee et al., 2002).

Here, we report that, in an FXS mouse model, group I mGluRmediated epileptogenic responses, normally activatable only by an exogenous agonist, were elicited by synaptic activities. The unleashing of a synaptic mechanism for group I mGluRmediated epileptogenesis may also be operational in vivo, because fragile $\mathrm{X}$ mice have enhanced audiogenic seizure susceptibility 
(Musumeci et al., 2000; Chen and Toth, 2001; Yan et al., 2004) and this form of seizure can be suppressed by an mGluR5 antagonist (Yan et al., 2005). Our finding is also relevant to an understanding of the FXS, because $\sim 25 \%$ of fragile X patients suffer from epilepsy during development (Musumeci et al., 1999; Sabaratnam et al., 2001).

\section{Materials and Methods}

Animals. Male $\mathrm{F}_{1}$ hybrid mice were obtained from crosses of male C57BL/fmr1-tm1Cgr mice and FVB/fmr1-tm1Cgr female mice $(\mathrm{C} 57 \times$ FVB) to produce Fmr1 knock-out (ko) mutant mice (Yan et al., 2004). Control animals were wild-type C57 $\times$ FVB. Three- to 4-week-old animals were used.

Slice preparation. Transverse hippocampal slices (400 $\mu \mathrm{m}$ thick) were prepared as described previously (Bianchi and Wong, 1995; Lee et al., 2002) and placed on the nylon mesh of an interface recording chamber (Fine Science Tools, Vancouver, British Columbia, Canada). The artificial CSF (ACSF) contained the following (in mM): $157 \mathrm{Na}^{+}, 136 \mathrm{Cl}^{-}, 5$ $\mathrm{K}^{+}, 1.6 \mathrm{Mg}^{2+}, 2 \mathrm{Ca}^{2+}, 26 \mathrm{HCO}_{3}^{-}$, and $11 \mathrm{D}$-glucose. Slices were perfused with ACSF continuously bubbled with $95 \% \mathrm{O}_{2} / 5 \% \mathrm{CO}_{2}$ to maintain the $\mathrm{pH}$ near 7.4. The temperature was maintained at $34-36^{\circ} \mathrm{C}$.

Electrophysiological recordings. In all experiments, the slices were allowed to recover from the isolation procedure for at least $1.5 \mathrm{~h}$ before the beginning of the recordings. Intracellular recordings were performed using an Axoclamp 2A amplifier (Molecular Devices, Palo Alto, CA). Electrodes were pulled with thin-walled glass tubing (World Precision Instruments, Sarasota, FL) and had resistances of 30-50 M $\Omega$ when filled with potassium acetate $(2 \mathrm{M})$. Some extracellular recordings were obtained with 3-8 M $\Omega$ electrodes filled with ACSF. Voltage signals were digitized and stored in an Intel Pentium-based computer using a Digidata 1322A converter controlled by pClamp 8 software (Molecular Devices).

Pharmacological agents. Baseline epileptiform activities for experiments in wild-type and $F m r 1$ ko mice hippocampal slices were elicited by continuous bath perfusion of the $\mathrm{GABA}_{\mathrm{A}}$ antagonist bicuculline $(50 \mu \mathrm{M})$. In another group of wild-type slices, the group I mGluR agonist DHPG $(50 \mu \mathrm{M})$ was used to induce synchronized activities. DHPG, the mGluR5selective antagonist 2-methyl-6-(phenylethynyl)-pyridine hydrochloride (MPEP) $(50 \mu \mathrm{M})$, the mGluR1-selective antagonist $(S)-(+)-\alpha$ amino-4-carboxy-2-methylbenzeneacetic acid (LY367385) (50 $\mu \mathrm{M})$, the translation inhibitors anisomycin and cycloheximide (15-20 and $60 \mu \mathrm{M}$, respectively), and transcription inhibitor actinomycin D $(25 \mu \mathrm{M})$ were obtained from Tocris Cookson (Ellisville, MO). 2-(2-Amino-3methyoxyphenyl)-4H-1-benzopyran-4-one (PD98059) (50 $\mu \mathrm{M})$ was from Calbiochem (La Jolla, CA). Bicuculline and the other chemicals were purchased from Sigma (St. Louis, MO). All agents were stored in stock solutions at $-80^{\circ} \mathrm{C}$ for no more than $1-2$ weeks and diluted into $\mathrm{ACSF}$ at the indicated final concentrations at the time of the experiments.

Data analysis. CA3 pyramidal cells included in this study had stable resting membrane potentials of less than $-60 \mathrm{mV}$, overshooting action potentials, and input resistance of $>30 \mathrm{M} \Omega$. In some cases, hyperpolarizing DC was injected into the cells to prevent intrinsic firing and identify network activities. The durations of individual synchronized discharges were measured from the beginning of the first action potential to the repolarization of the last action potential of the discharge at membrane potentials kept within a few millivolts throughout the experiment. In the frequency histogram plots, the durations of all synchronized discharges recorded in a 6 min period for each slice in the various experimental conditions were included. The histograms were fitted with first- or second-order Gaussian equations. Based on the distribution of the synchronized discharge durations shown in Figure $1 \mathrm{Dbi}$, "short" and "prolonged" discharges refer to events shorter and longer, respectively, than 1.5 s. Clampfit 8 (Axon Instruments) and Sigma Plot (SPSS, Chicago, IL) software were used for all data analysis. Average data were expressed as mean \pm SEM. Student's $t$ test was used for statistical comparisons, and differences were considered significant when $p<0.05$.

\section{Results}

Bath application of bicuculline $(50 \mu \mathrm{M})$ to a hippocampal slice prepared from a wild-type mouse first induced occasional synchronized discharges with a mean duration of $0.573 \pm 0.026 \mathrm{~s}$ (short synchronized discharges; $n=20$ ) in the CA3 area. Within $10 \mathrm{~min}$, the short synchronized discharges began to occur regularly and rhythmically (frequency range, $0.042-0.123 \mathrm{~Hz} ; n=25$ discharges) (Fig. $1 \mathrm{Aa}$ ). Overall, the frequency and duration of the short synchronized discharges remained stable for at least $2 \mathrm{~h}$ in all preparations examined $(n=10)$ (Fig. $1 A, C, D a)$. The average duration of short synchronized discharges recorded $\sim 2 \mathrm{~h}$ after their initial appearance was $0.625 \pm 0.021 \mathrm{~s}(n=30$ discharges $)$ (Fig. $1 A b$ ), a value not significantly different from that recorded when they first appeared ( $p=0.122$; Student's $t$ test).

Figure $1 B$ shows records obtained from hippocampal slices prepared from Fmr1 ko mice. Addition of bicuculline $(50 \mu \mathrm{M})$ elicited an initial period of short rhythmic synchronized discharges with average duration of $0.627 \pm 0.021 \mathrm{~s}$, not significantly different from that recorded in the wild-type slice. In contrast to the events recorded from wild-type slices, in all of the Fmr1 ko preparations, a variable initial period of 5-40 min was followed by sporadic prolongation of the short synchronized discharges interspersed between the regular rhythmic short synchronized discharges. Prolonged discharges were considered to be extended from short discharges for two reasons: (1) they occurred at the time point at which a short synchronized discharge would have occurred as predicted by the ongoing rhythmicity, and (2) the initial action potential pattern of a prolonged discharge resembled that of the short synchronized discharge (Fig. $1 B$, compare $a$, $b$ ), suggesting that the prolonged discharge was triggered through a mechanism initiated by the short synchronized discharge. Over time, the frequency and duration of the prolonged discharges increased (Fig. 1C), and, by 90 min of bicuculline perfusion, the prolonged discharges occurred at regular rhythms (frequency range, $0.011-0.021 \mathrm{~Hz} ; n=6$ ) and became the dominant spontaneous event (Fig. $1 B b$, inset; $C$ ). Figure $1, B b$ and $C$, shows that prolonged synchronized discharges at $\sim 2 \mathrm{~h}$ of perfusion with bicuculline were significantly longer $(6.347 \pm 0.021 \mathrm{~s} ; n=6$ discharges) than the short synchronized discharges $(p \ll 0.001)$. Often, even when the prolonged discharges became rhythmic, short-duration discharges were still observed and they coexisted with the prolonged discharges (Fig. $1 B b$, inset; $C$ ). Population data from 21 Fmrl ko mice indicate that, after $>80$ min of bicuculline application, in all preparations short and prolonged synchronized discharges are distributed into two relatively distinct groups (Fig. $1 \mathrm{Dbi}$ ), and the longest discharges are significantly prolonged compared with those recorded at the beginning of their appearance (Fig. 1 Dbii).

Prolongation of the bicuculline-induced short synchronized discharges is an event unique to the Fmr1 ko preparation. In the wild-type preparation, prolongation of the short synchronized discharges induced by bicuculline was observed only after addition of the group I mGluR agonist DHPG $(25-50 \mu \mathrm{M})$. The DHPG-induced prolonged synchronized discharges have two distinct properties: (1) the extended discharges are sustained by activation of group I mGluRs (Merlin and Wong, 1997), and (2) the induction of the events is protein synthesis dependent (Merlin et al., 1998). It is possible that the bicuculline-induced prolonged synchronized discharges in Fmrl ko slices are also dependent on the group I mGluR-mediated mechanism that is now triggered by synaptically released glutamate, without the need for 
A

a

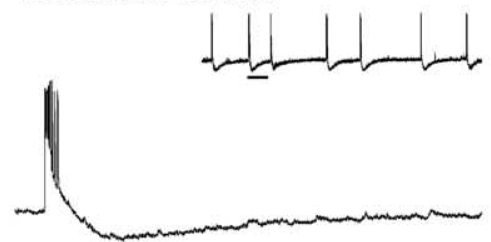

Bicuculline 20 min
Wild type

\section{$b_{B}$}

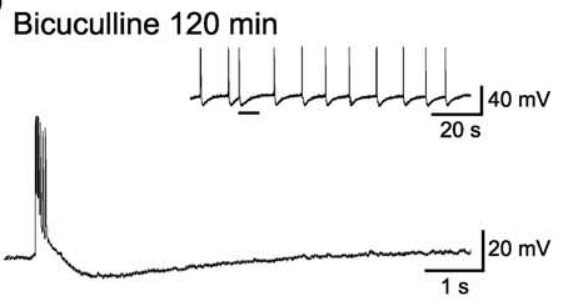

B

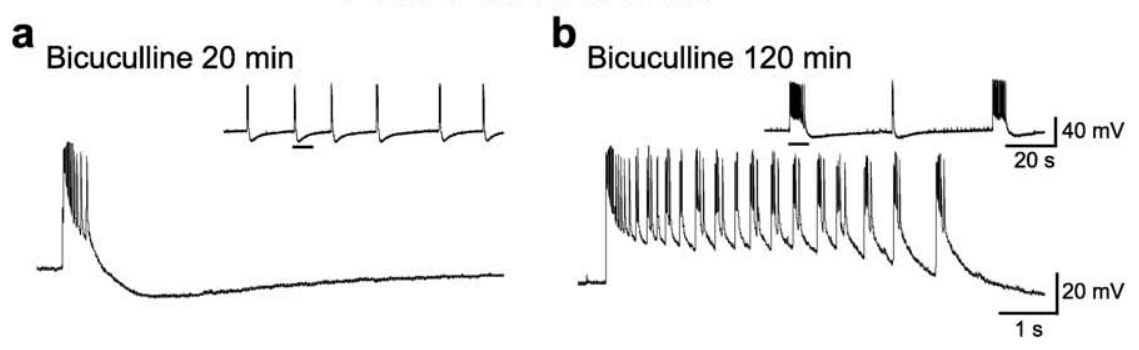

C

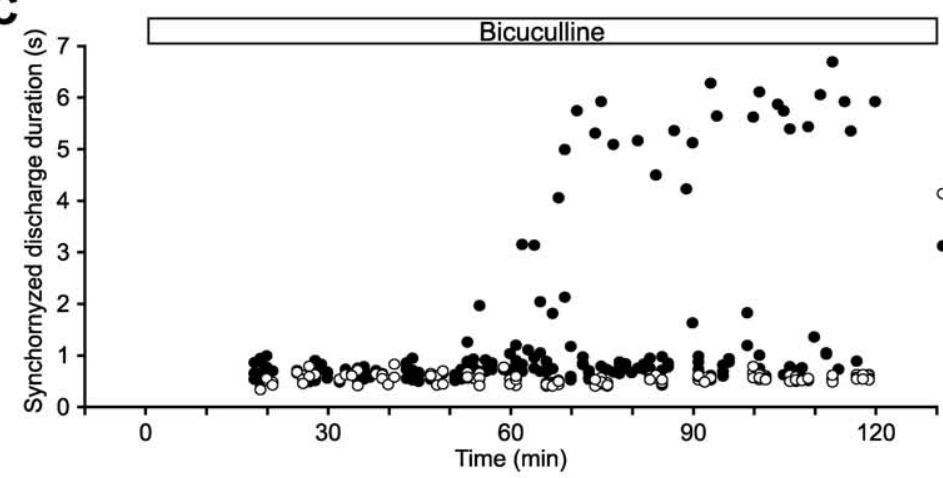

D
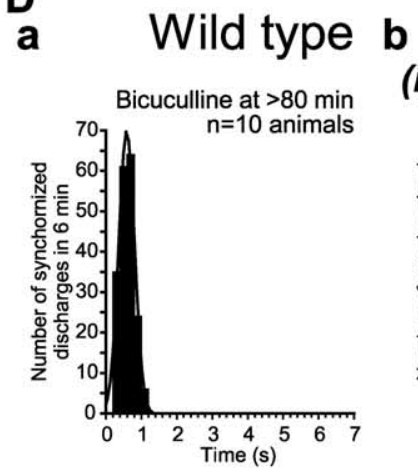

Fmr1 knockout

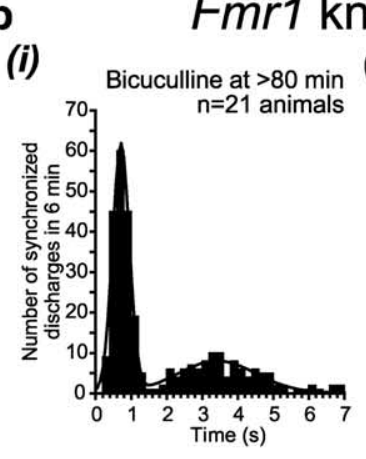

(ii)
-Wild type

- Fmr1 knockout

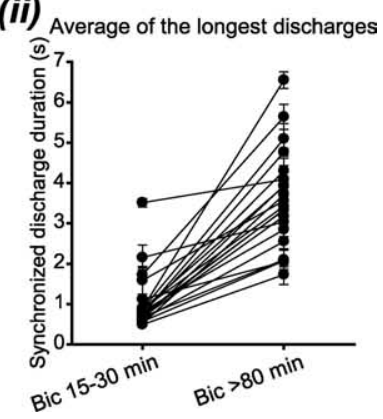

Figure 1. Prolonged epileptiform discharges in the CA3 region of hippocampal slices from $F m r 1$ knock-out mice after $G A B A_{A}$ receptor blockade. $A$, Intracellular recordings of the spontaneous activity of a CA3 pyramidal cell in a wild-type mouse hippocampal slice after addition of the $\mathrm{GABA}_{\mathrm{A}}$ receptor antagonist bicuculline $(50 \mu \mathrm{M})$ to the perfusate. Within $20 \mathrm{~min}$, bicuculline induced rhythmic, short discharges $(\boldsymbol{a})$ that were ongoing for at least $2 \mathrm{~h}$ of continuous recording $(\boldsymbol{b})$. Here and in $\boldsymbol{B}$, as well as in Figures 2 , $A$ and $B$, and $3, A$ and $B$, the single short discharges illustrated in the main panels are expanded records of the events indicated by the bars in the corresponding insets. These discharges reflected synchronized network activities, because they were recorded at membrane potentials less than $-70 \mathrm{mV}$, they did not change in frequency at different membrane potential levels, and they were recorded with extracellular electrodes (data not shown). Membrane potentials at the beginning of the recordings were as follows: $-61 \mathrm{mV}(\boldsymbol{a}) ;-64 \mathrm{mV}(\boldsymbol{b})$. Burst frequency at $120 \mathrm{~min}$ bicuculline appeared greater than that at $20 \mathrm{~min}$. However, no significant change in burst frequency was observed in the overall population (see Results). $B$, CA3 intracellular recordings from an $F m r 1$ ko slice after bicuculline addition $(50 \mu \mathrm{m})$. Bicuculline first induced short synchronized discharges $(\boldsymbol{a})$ that were similar to those recorded in wild-type slices. Continuous exposure to bicuculline $(\boldsymbol{b})$, in contrast to what was observed in wild-type experiments, also induced prolonged synchronized discharges of $5-7 \mathrm{~s}$ in duration. Membrane potentials were as follows: $-62 \mathrm{mV}(\boldsymbol{a}) ;-65$ $\mathrm{mV}(\boldsymbol{b})$. C, Time course of the duration of synchronized bursts recorded in the cells shown in $\boldsymbol{A}$ (open circles) and in $\boldsymbol{B}$ (filled added DHPG. If this were the case, the prolonged discharges elicited by bicuculline in the Fmrl ko mice should be pharmacologically similar to those elicited in the wild-type slices after DHPG stimulation (i.e., suppressed by group I mGluR antagonists), and their induction should be sensitive to translation inhibitors. We tested these two possibilities.

The effectiveness of MPEP, a blocker of the group I mGluR subtype mGluR5, on synchronized discharges elicited by bicuculline was examined. In the wild-type preparations, addition of MPEP $(50 \mu \mathrm{M})$ did not significantly affect the duration of rhythmic short synchronized discharges observed after $80 \mathrm{~min}$ of bicuculline treatment (bicuculline, 80 min: $0.478 \pm 0.014$ s; $n=7$; bicuculline plus MPEP, $60 \mathrm{~min}$ : $0.454 \pm 0.011 \mathrm{~s} ; n=10 ; p=0.203$ ) (Fig. $2 A a, A b, C)$. Figure $2, B$ and $C$, shows results obtained from hippocampal slices prepared from an Fmrl ko mouse. Rhythmic short synchronized discharges initially elicited by bicuculline developed into mainly prolonged synchronized discharges by $\sim 80$ min of maintained bicuculline perfusion (duration, $4.230 \pm 0.111$ $s ; n=7$ ) (Fig. $2 B a, C$ ). Within 30 min after MPEP perfusion, the prolonged discharges shortened significantly (bicuculline plus MPEP, $60 \mathrm{~min}: 0.534 \pm 0.012 \mathrm{~s}$; $n=6 ; p \ll 0.001)$ and the spontaneous activities reverted back to rhythmic short synchronized discharges (Fig. 2Bb,C). Summary data from slices prepared from seven Fmrl ko animals show that most slices exhibited rhythmic patterns of short and prolonged synchronized discharges after 80 min of bicuculline perfusion (Fig. 2 Dbi). Addition of MPEP after the $80 \mathrm{~min}$ time point suppressed the prolonged synchronized discharges, leaving behind

\section{$\leftarrow$}

circles). The top bar indicates presence of bicuculline in the perfusate. $D$, Frequency histograms of all synchronized bursts recorded during a 6 min period of stable rhythmic activity, starting at a time point after 80 min of perfusion with bicuculline, in slices from 10 wild-type mice (a) and from $21 \mathrm{Fmr} 1$ ko mice (bi). Note that, in wild-type slices, synchronized discharges were normally distributed with an average duration of $0.588 \pm 0.005 \mathrm{~s}$ (first-order Gaussian fit; $r=0.91$ ), whereas in Fmr 1 ko slices, a two-peak distribution indicated a group of short synchronized discharges with average duration of $0.704 \pm 0.007 \mathrm{~s}$ and a group of prolonged synchronized discharges of $3.399 \pm 0.134$ s (second-order Gaussian fit; $r=0.88)$. $\boldsymbol{b i i}$, Each symbol with a vertical bar represents the average duration and SEM of the five longest synchronized discharges recorded during a 6 min period in each slice from 21 Fmr 1 ko animals. In all cases, the duration of the longest synchronized discharges at $>80$ min of bicuculline perfusion was significantly increased compared with that at 15-30 min bicuculline. Bic, Bicuculline. 


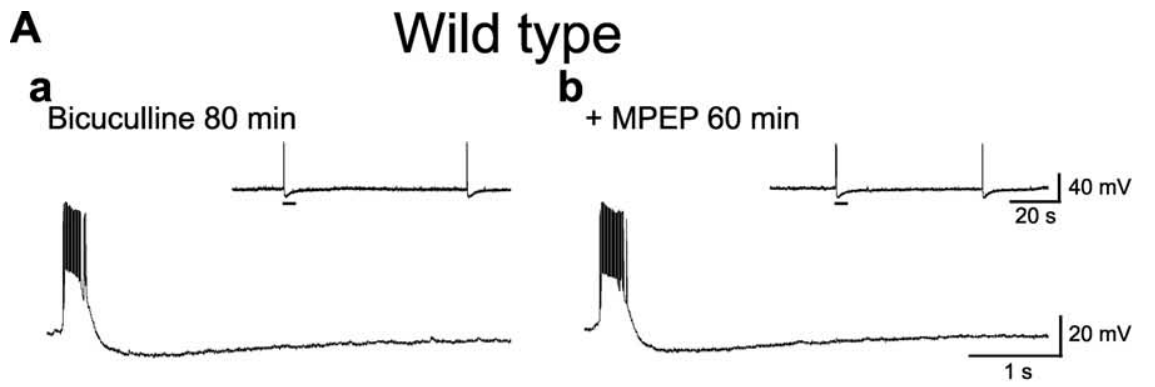

B $\quad$ Fmr1 knockout
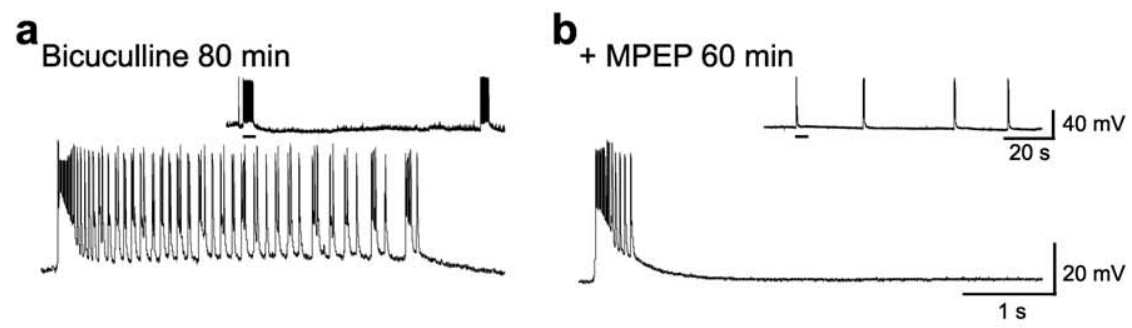

C

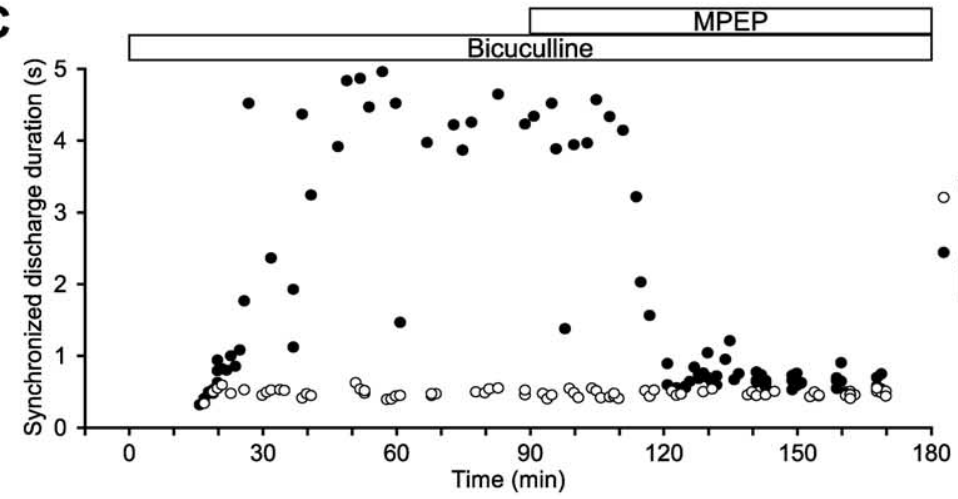

D a Wild type b

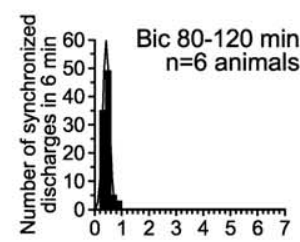

\section{(i)}

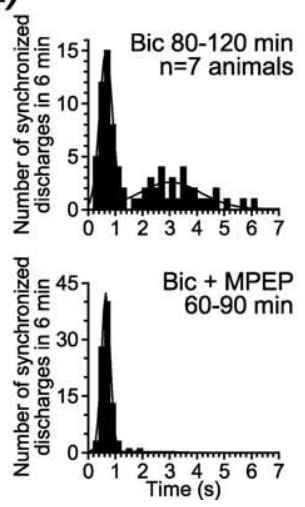

Fmr1 knockout

(ii)

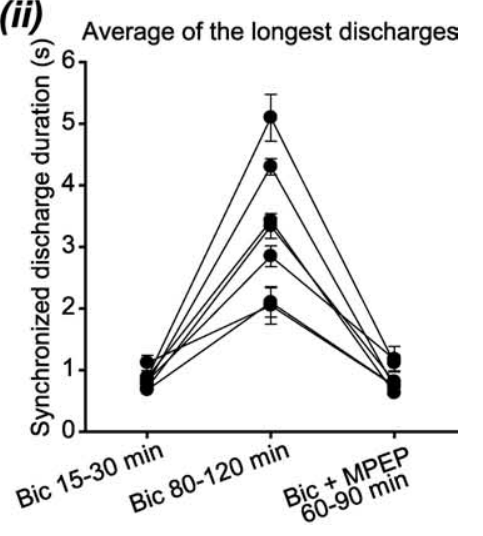

Figure 2. The mGluR5 antagonist MPEP suppresses the prolonged synchronized discharges in disinhibited Fmr 1 knock-out slices. $A$, Intracellular recordings of CA3 short synchronized discharges in a wild-type slice, after $80 \mathrm{~min}$ of perfusion with bicuculline $(\boldsymbol{a})$ and $60 \mathrm{~min}$ after the addition of the mGluR5 antagonist MPEP $(50 \mu \mathrm{m} ; \boldsymbol{b})$ to the perfusate. Membrane potentials were as follows: $-65 \mathrm{mV}(\boldsymbol{a}) ;-63 \mathrm{mV}(\boldsymbol{b})$. B, Intracellular recordings of prolonged epileptiform discharges in CA3 pyramidal cells of an Fmr 1 ko slice induced by $80 \mathrm{~min}$ of perfusion with bicuculline $(\boldsymbol{a})$. Sixty minutes after MPEP application, only short synchronized discharges were recorded. Membrane potentials were as follows: $-74 \mathrm{mV}(\boldsymbol{a}) ;-73 \mathrm{mV}(\boldsymbol{b})$. C, Time course of the duration of synchronized bursts recorded in the cells shown in $\boldsymbol{A}$ (open circles) and in $\boldsymbol{B}$ (filled circles). Top bars indicate presence of bicuculline and MPEP in the perfusate. In the Fmr 1 ko slice, after $30 \mathrm{~min}$, MPEP reduced the length of the prolonged synchronized discharges to short synchronized discharges similar to those recorded in the wild-type slice. $\boldsymbol{D}$, Frequency histograms of all synchronized discharges recorded during a 6 min period, at $\sim 80-120$ min of perfusion with bicuculline (top histograms) and at $60-90$ min after the addition of MPEP to the perfusate (bottom histograms), in slices from six wild-type mice (a) and from seven Fmr 1 ko mice (bi). In wild-type slices, the average burst durations from the peaks of the first-order Gaussian fits were $0.425 \pm$ rhythmic short synchronized events at an accelerated frequency (Fig. $2 B b, D b$ ). In wild-type preparations, MPEP did not significantly affect the duration of short synchronized discharges recorded after 80 min of bicuculline treatment (Fig. 2Da).

LY367385 $(50 \mu \mathrm{M})$, an antagonist of the other group I mGluR subtype mGluR1, was also effective in suppressing bicuculline-induced prolonged synchronized discharges in Fmr1 ko preparations. In four experiments, the five longest discharges in a $6 \mathrm{~min}$ period after $80-120 \mathrm{~min}$ of bicuculline perfusion were $6.107 \pm$ $0.735,3.599 \pm 0.054,5.907 \pm 0.171$, and $5.855 \pm 0.246 \mathrm{~s}$. After $60-90 \mathrm{~min}$ of LY367385 application, the five longest discharges were $0.440 \pm 0.027,1.056 \pm 0.051$, $0.675 \pm 0.032$, and $4.191 \pm 0.248 \mathrm{~s}$, respectively ( $p<0.01$ in all cases).

Previous data show that, in hippocampal slices prepared from guinea pigs, agents that inhibit mRNA translation such as anisomycin and cycloheximide prevented the activation of prolonged synchronized discharges by DHPG (Merlin et al., 1998). We reevaluated the action of these inhibitors on wild-type mouse preparations.

Addition of DHPG to hippocampal slices elicited a phase of short rhythmic synchronized discharges, which gradually evolved into a mixed pattern of short and prolonged discharges. After $\sim 40 \mathrm{~min}$ of DHPG perfusion, the spontaneous synchronized activity settled into a rhythmic pattern of primarily prolonged discharges with interspersed short discharges (Fig. $3 A a)$. This activity was ongoing relatively unaltered for up to $4 \mathrm{~h}$ (the longest period recorded). The average duration of the prolonged discharges (4.559 $\pm 0.114 \mathrm{~s}$; $n=17$ ) (Fig. $3 A d ; C$, top panel) was similar to that of bicuculline-induced prolonged discharges in Fmr1 ko slices (Fig. 1 Bb,Dbi). Pretreatment of hippocampal slices with 20 $\mu \mathrm{M}$ anisomycin for $1 \mathrm{~h}$ before the addition of

$\leftarrow$

$0.002 \mathrm{~s}(r=0.94)$ before MPEP and $0.371 \pm 0.014 \mathrm{~s}(r=$ 0.85) after 60-90 min of MPEP. In Fmr 1 ko slices, the twopeak distribution $(r=0.81)$ before MPEP shows a group of short synchronized discharges of $0.653 \pm 0.012 \mathrm{~s}$ and a group of prolonged synchronized discharges of $3.015 \pm$ 0.159 s. After $60-90$ min of MPEP, the prolonged synchronized discharges were suppressed and a group of short synchronized discharges with a peak at $0.650 \pm 0.002$ s duration $(r=0.85)$ remained. bii, Summary plot of the average duration of the five longest synchronized discharges recorded during a 6 min period in slices from seven Fmr 7 ko animals at the indicated times. In all experiments, the longest synchronized discharges were prolonged by $80-120$ min of bicuculline perfusion and were then significantly reduced in duration by addition of MPEP. Bic, Bicuculline. 
A

\section{a} Wild type in ACSF

Control
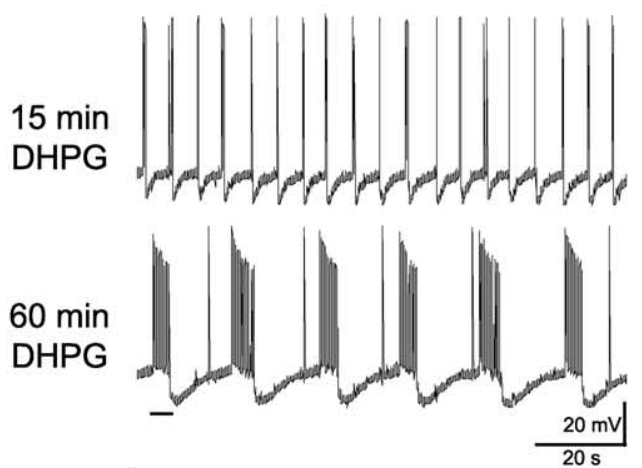

d

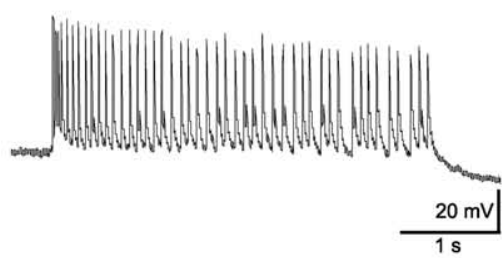

b

Wild type in anisomycin
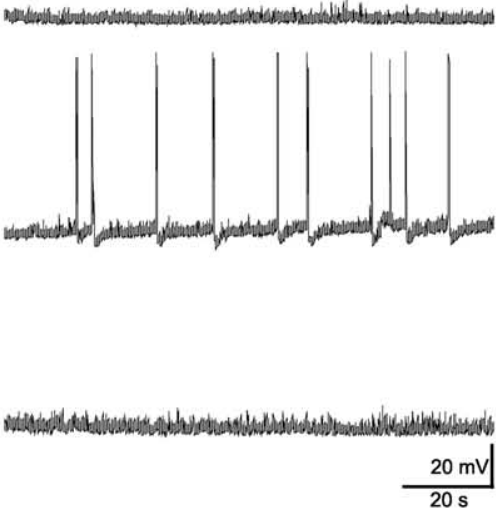

e

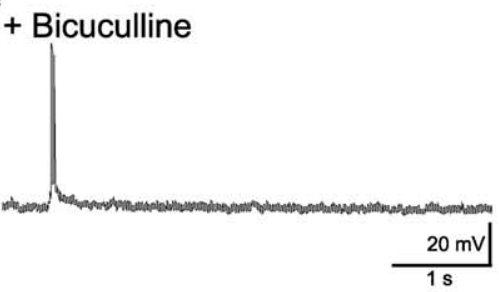

C Wild type in actinomycin D

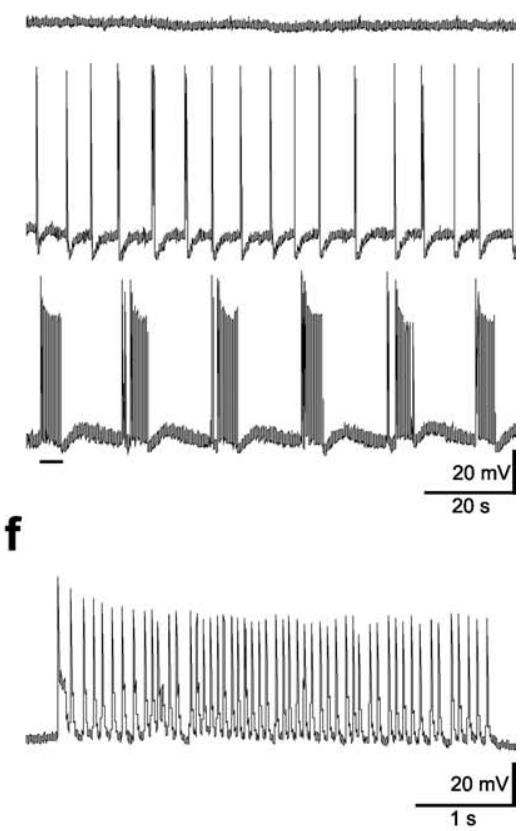

B

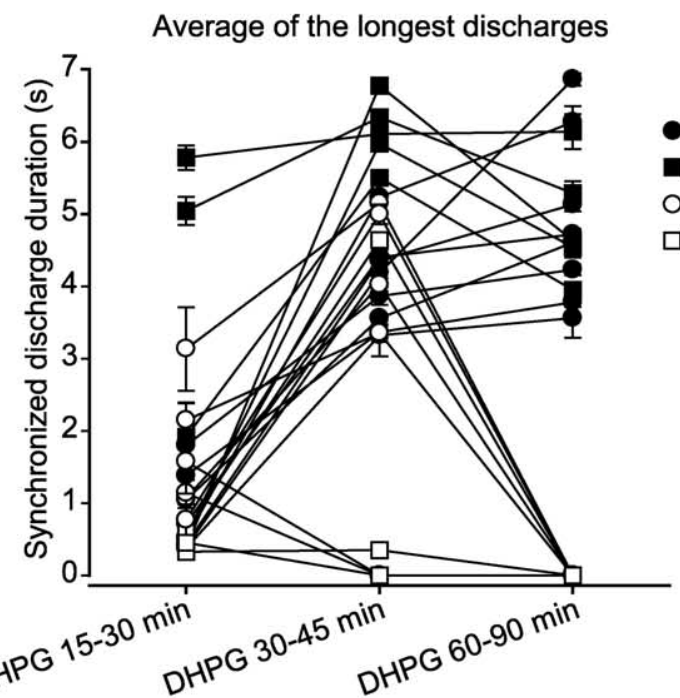

In ACSF

In actinomycin D

O In anisomycin

$\square$ In cycloheximide
C
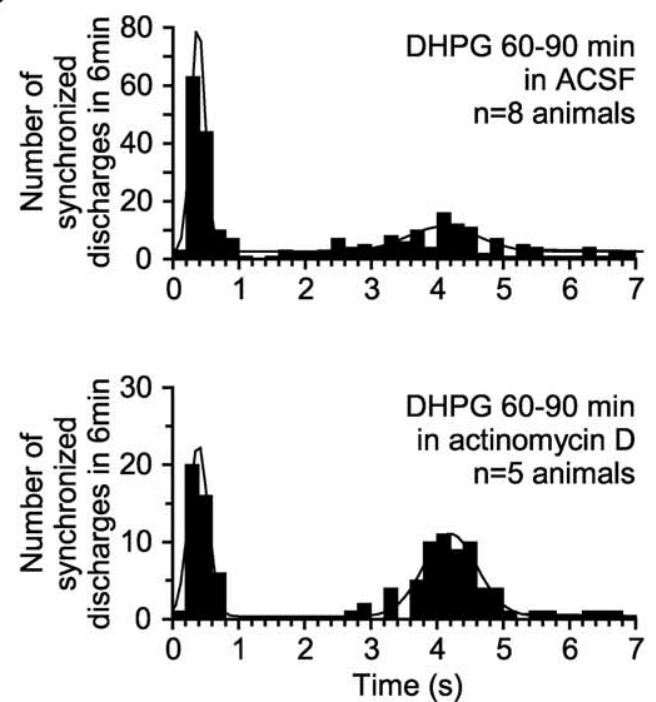

Figure 3. Inhibitors of mRNA translation suppress induction of prolonged synchronized discharges by DHPG in wild-type slices. $A$, Effects of the group I mGluR agonist DHPG ( $50 \mu \mathrm{M}$ ) on the spontaneous activity of CA3 pyramidal cells in wild-type mouse slices that were perfused with ACSF without (a) or with the translation inhibitor anisomycin (20 $\mu \mathrm{m} ; \boldsymbol{b})$ or with the transcription inhibitor actinomycin D $(25 \mu \mathrm{m} ; \boldsymbol{c})$. The inhibitors were present in the perfusing solution for at least $1 \mathrm{~h}$ before the addition of DHPG and during perfusion with DHPG. $\boldsymbol{a}$, As described previously (Zhao et al., 2004), DHPG induced first short synchronized bursts (15 min DHPG) and then prolonged epileptiform discharges (60 min DHPG). $\boldsymbol{b}$, In the presence of anisomycin, no epileptiform discharges were recorded after $60 \mathrm{~min}$ of DHPG (bottom panel). $c$, In the presence of actinomycin D, epileptiform activity after 60 min of DHPG was similar to that observed in ACSF. Prolonged epileptiform discharges indicated by the bars in $\boldsymbol{a}$ and $\boldsymbol{c}$, bottom panels, are expanded in $\boldsymbol{d}$ and $\boldsymbol{f}$, respectively. In the anisomycin-treated slice, addition of bicuculline (50 $\mu \mathrm{m}$ ) elicited short synchronized discharges, one of which is shown in $\boldsymbol{e}$. Membrane potentials (top to bottom): $-67,-64,-63 \mathrm{mV}(\boldsymbol{a}) ;-67,-66,-61 \mathrm{mV}(\boldsymbol{b}) ;-66,-63,-67 \mathrm{mV}(\boldsymbol{c}) ;-65 \mathrm{mV}(\boldsymbol{e})$. B, Summary plot of the average duration of the five longest synchronized discharges recorded during a $6 \mathrm{~min}$ period at the indicated time after addition of DHPG in wild-type slices perfused with ACSF (filled circles; $n=$ 8), or treated with actinomycin D ( $25 \mu \mathrm{m}$; filled squares; $n=5)$, with anisomycin ( $20 \mu \mathrm{m} ;$ open circles; $n=6)$, or with cycloheximide ( $60 \mu \mathrm{m}$; open squares). Inhibitors were applied for at least $1 \mathrm{~h}$ before the addition of DHPG and were present throughout the experiment. Note that inhibitors of translation, but not of transcription, eventually suppressed the DHPG-induced synchronized discharges. C, Frequency histograms of all synchronized bursts recorded in wild-type slices during a 6 min period, at $\sim 60-90$ min of DHPG application in the absence of actinomycin D (top histogram) and in the presence of actinomycin D (bottom histogram). Second-order Gaussian fits of the events in ACSF ( $r=0.80)$ and in actinomycin D ( $r=0.81$ ) show short synchronized discharges (ACSF, $0.376 \pm 0.008 \mathrm{~s}$; actinomycin D, $0.400 \pm 0.009 \mathrm{~s}$ ) and prolonged synchronized discharges (ACSF, $4.064 \pm 0.111 \mathrm{~s}$; actinomycin D, $4.224 \pm 0.038 \mathrm{~s}$ ) of similar durations.

DHPG prevented the appearance of prolonged discharges in two of six slices. In the remaining preparations treated with anisomycin, short discharges evolved into prolonged ones, but rhythmic prolonged discharges appeared only transiently for a period of 10-30 min, and by 60 min of DHPG in none of the slices was synchronized activity observed (Fig. 3Ab,B). This was unlikely attributable to nonspecific effects on synchronizing mechanisms of the CA3 network, because bicuculline addition to anisomycin-treated slices did elicit 


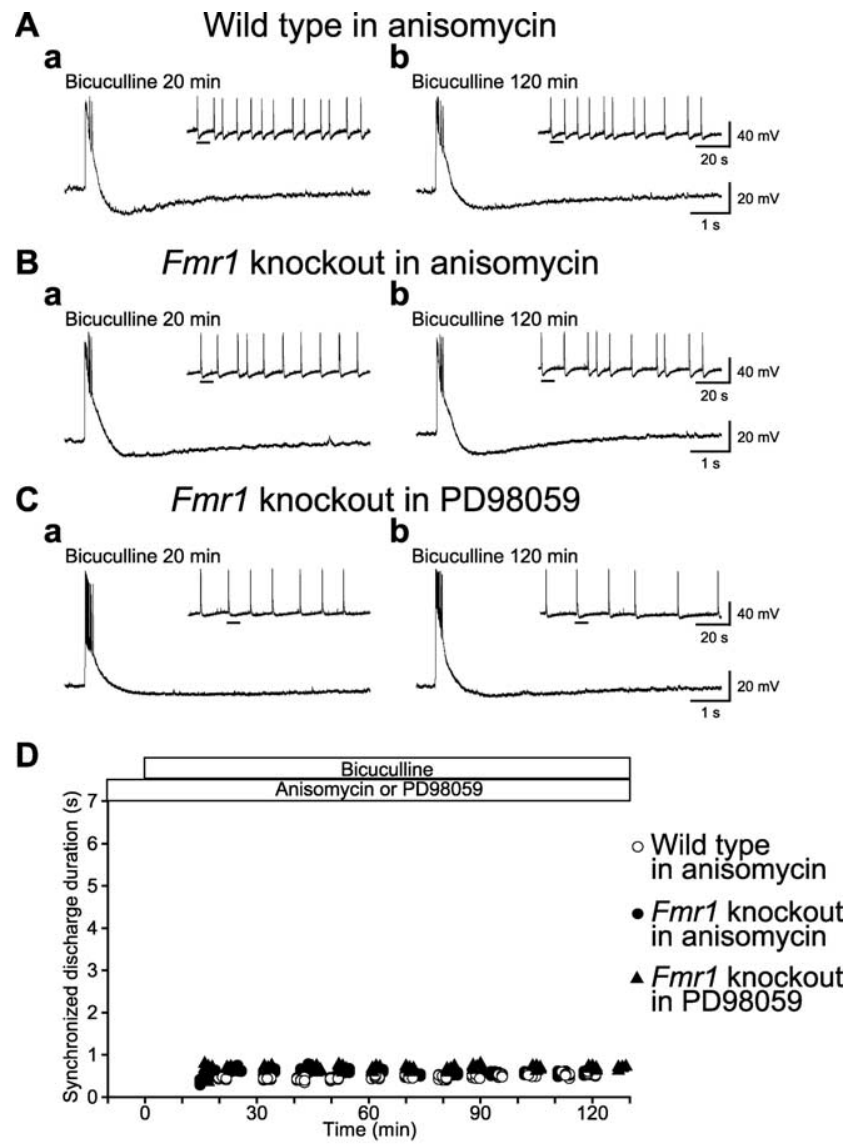

E

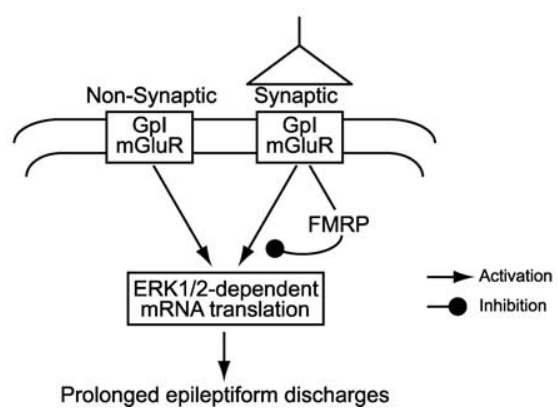

Figure 4. Induction of prolonged synchronized discharges in Fmr 1 knock-out slices depends on synaptic activation of group I mGluR-mediated $m R N A$ translation. $\boldsymbol{A}, \boldsymbol{B}$, Intracellular recordings of the spontaneous activity of CA3 pyramidal cells from a wild-type mouse hippocampal slice $(\boldsymbol{A})$ and from an Fmr 7 ko slice $(\boldsymbol{B})$, after $20 \mathrm{~min}(\boldsymbol{a})$ and $120 \mathrm{~min}(\boldsymbol{b})$ of bicuculline $(50 \mu \mathrm{M})$ applied in the presence of anisomycin $(20 \mu \mathrm{M})$. Before bicuculline application, slices were pretreated with anisomycin for at least 1h. Membrane potentials were as follows: $-66 \mathrm{mV}(\boldsymbol{A a}) ;-65 \mathrm{mV}(\boldsymbol{A} \boldsymbol{b}) ;-67 \mathrm{mV}(\boldsymbol{B a}) ;-69 \mathrm{mV}$ $(B \boldsymbol{B b})$. C, Intracellular recordings of the spontaneous activity of a $C A 3$ pyramidal cell from an $F m r 1 \mathrm{ko}$ slice after $20 \mathrm{~min}(\boldsymbol{a})$ and $120 \mathrm{~min}(\boldsymbol{b})$ of bicuculline $(50 \mu \mathrm{m})$ applied in the presence of the MEK inhibitor PD98059 $(50 \mu \mathrm{m})$. Before bicuculline application, the slice was pretreated with PD98059 for $\sim 1 \mathrm{~h}$. Membrane potentials were as follows: $-69 \mathrm{mV}(\boldsymbol{a}) ;-70 \mathrm{mV}(\boldsymbol{b})$. D, Time course of the duration of the synchronized discharges recorded in the three experiments shown in $\boldsymbol{A}$ (open circles), in $\boldsymbol{B}$ (filled circles), and in C (filled triangles). No prolonged synchronized discharges were observed in anisomycin- or PD98059-treated slices, whereas short synchronized activity occurred apparently unaltered in both wild-type and $F m r 1$ ko preparations. Additional experiments showed that the mean durations of synchronized discharges after $80-120$ min bicuculline in wild-type slices in anisomycin $(0.450 \pm 0.025 \mathrm{~s} ; n=7)$, in Fmr 1 ko slices in anisomycin $(0.491 \pm 0.060 \mathrm{~s} ; n=8)$, and in Fmr 1 ko slices in PD98059 (0.484 $\pm 0.039 ; n=9)$ were not significantly different from the duration of synchronized discharges after $80-120$ min bicuculline in wild-type slices that were not pretreated with inhibitors of mRNA translation or MEK $(0.560 \pm 0.055 s ; n=10)$. $E$, Summary scheme of FMRP regulation of group I (GPl) mGluR synaptic responses. In the wild-type CA3 area, the FMRP suppression of group I mGluR-mediated responses occurs only at synapses and not at the extrasynaptic sites. Without the action of FMRP, as in fragile X preparations, unrestrained mRNA translation triggered by synaptic activation of group I mGluR, via ERK1/2 activation, leads to prolonged synchronized discharges. short synchronized discharges (Fig. 3Ae). Pretreatment of slices with cycloheximide ( $60 \mu \mathrm{M} ; n=3$ ) produced similar suppressive effects on the elicitation of DHPG-mediated prolonged discharges (Fig. 3B). Thus, inhibitors of mRNA translation antagonized the generation of DHPG-induced prolonged discharges. In contrast, pretreatment of slices with actinomycin D $(25 \mu \mathrm{M})$, a transcription inhibitor, did not affect prolonged discharge activities elicited by DHPG (Fig. 3Ac,Af) (duration, $4.309 \pm 0.071 \mathrm{~s} ; n=16$ ) (Fig. $3 C$, bottom panel). The results suggest that active translation is required for the generation of DHPG-activated prolonged discharges.

Prolonged discharges observed in bicuculline-treated Fmrl ko hippocampal slices were also suppressed by anisomycin pretreatment (Fig. $4 B, D$ ). Rhythmic short synchronized discharges were the only activity pattern recorded under this condition. Thus, in the presence of anisomycin, bicuculline elicited similar responses in Fmrl ko preparations as those elicited by bicuculline in wildtype preparations. Additional experiments showed that anisomycin pretreatment did not affect the time course of short synchronized discharges in the wild-type preparation (Fig. 4A,D). The results suggest that the generation of short synchronized discharges in the wild-type and Fmrl ko bicuculline-treated preparations is protein synthesis independent. Generation of bicuculline-mediated prolonged discharges, however, is dependent on a mRNA translation, a process that is activatable only in the Fmrl ko preparations.

Previous studies show that, in wild-type slices, the induction of prolonged synchronized discharges by DHPG requires activation of the extracellular signal-regulated kinase 1/2 (ERK1/2) (Zhao et al., 2004). We examined whether ERK1/2 is also involved in the activation of bicuculline-induced prolonged synchronized discharges in the Fmrl ko hippocampal slices. Inhibition of ERK1/2 was attempted with pretreatment of the slices with the mitogen-activated protein kinase kinase (MEK) inhibitor PD98059 $(50 \mu \mathrm{M})$. In these slices, only short synchronized discharges were observed in bicuculline for periods of up to $2 \mathrm{~h}$ (Fig. $4 C, D$ ).

\section{Discussion}

The results show that prolonged synchronized discharges evoked by bicuculline in Fmrl ko hippocampal slices share similar properties with the prolonged synchronized discharges activated by the group I mGluR agonist DHPG in wild-type slices. The data suggest that, in the Fmrl ko preparation, synaptically released glutamate is effective in inducing group I mGluR-mediated prolonged synchronized discharges.

In the wild-type preparation, group I mGluRs are activated by DHPG. The activation of the receptors initiates the signaling cascade and, via protein synthesis, induces the prolonged synchronized discharges. Signaling through this cascade is probably the limiting step in the period required for the expression of the fully extended prolonged synchronized discharges. In Fmrl ko preparations, group I mGluRs are activated by synaptic glutamate synchronously released in the presence of bicuculline. Activation of group I mGluRs in the ko was effective in initiating the signaling cascade for the protein synthesis-dependent induction of the prolonged synchronized discharges. Prolonged synchronized discharges appeared after a latent period of 5-40 min after the appearance of the short synchronized discharges. This period of time may again reflect translation processes necessary for the induction of prolonged synchronized discharges. Thus, the prolonged synchronized discharges induced by DHPG in wild-type 
slices and those induced by bicuculline in Fmrl ko slices appear to share a common mechanism dependent on the group I mGluRactivated protein translation process.

In hippocampal neurons of wild-type preparations, group I mGluRs are activated synaptically during evoked responses (Nakamura et al., 1999) and during bicuculline-induced short synchronized discharges (Lee et al., 2002). However, despite such synaptic activation, group I mGluR-mediated prolonged discharges are not elicited in bicuculline. Lee et al. (2002) showed that, in the wild-type preparation, synaptically activated group I mGluR responses mainly result from the direct actions of the receptor-coupled G-proteins and do not involve phospholipase C $\beta 1$ (PLC $\beta 1$ ) activation and the signaling cascade downstream to PLC $\beta 1$ activation. Group I mGluR-activated mRNA translation is probably ERK $1 / 2$ dependent (Fig. $4 C, D$ ) and requires signaling downstream to PLC $\beta 1$ activation (Zhao et al., 2004). Thus, synaptic stimulation of group I mGluRs may not be effective in activating mRNA translation and the resulting prolonged synchronized discharges in the wild-type hippocampal neurons. The unleashing of this process in the Fmrl ko preparation suggests that synaptically induced prolonged synchronized discharges and the associated mRNA translation are repressed by FMRP (Fig. 4E). A similar role of FMPR in downregulating a group I mGluR-induced, translation-dependent long-term depression has led to the hypothesis that exaggerated group I mGluR function is a fundamental abnormality in fragile $\mathrm{X}$ syndrome (Bear et al., 2004). Our results provide an additional example to this general concept and extend the hypothesis to include epileptogenesis as a possible outcome of an exaggerated group I mGluR function.

Epilepsy is a syndrome suffered by $\sim 25 \%$ of fragile $\mathrm{X}$ patients during development (Musumeci et al., 1999; Sabaratnam et al., 2001). Recent studies show that the susceptibility to audiogenic seizures is enhanced in Fmrl ko mice (Musumeci et al., 2000; Chen and Toth, 2001; Yan et al., 2004). In addition, these seizures are effectively suppressed by the mGluR5 antagonist MPEP (Yan et al., 2005). Our data suggest that the expression of prolonged synchronized discharges requires the contribution of both mGluR1 and mGluR5. Antagonism of either receptor subtype is effective in preventing the expression of prolonged synchronized discharges.

The epileptogenic property of synaptic group I mGluRs in the FXS mouse model is uncovered in our studies by using bicuculline to block $\mathrm{GABA}_{\mathrm{A}}$ receptor-mediated inhibition. It is possible that enhanced group I mGluR-mediated synaptic responses can also be recruited by intense neuronal activity in the Fmrl ko preparation to elicit epileptiform activities, particularly in view of the finding that $\mathrm{GABA}_{\mathrm{A}}$ receptor-mediated inhibition is downregulated in Fmrl ko mice (El Idrissi et al., 2005). As noted above, enhanced synaptic group I mGluR responses may indeed be operational to sustain increased audiogenic seizure susceptibility in the FXS mouse model (Yan et al., 2005).

In summary, our data are consistent with the emerging hypothesis that exaggerated group I mGluR translational responses contribute to synaptic abnormalities in fragile X syndrome (Bear et al., 2004). Together with available data, our findings suggest that FMRP regulation of synaptically induced group I mGluR-mediated mRNA translation is involved in the normal neuronal signaling and that the absence of such regulation, as in fragile X syndrome, could cause brain pathologies including epileptogenesis.

\section{References}

Aschrafi A, Cunningham BA, Edelman GM, Vanderklish PW (2005) The fragile $\mathrm{X}$ mental retardation protein and group I metabotropic glutamate receptors regulate levels of mRNA granules in brain. Proc Natl Acad Sci USA 102:2180-2185.

Bear MF, Huber KM, Warren ST (2004) The mGluR theory of fragile X mental retardation. Trends Neurosci 27:370-377.

Bianchi R, Wong RKS (1995) Excitatory synaptic potentials dependent on metabotropic glutamate receptor activation in guinea-pig hippocampal pyramidal cells. J Physiol (Lond) 487:663-676.

Caudy AA, Myers M, Hannon GJ, Hammond SM (2002) Fragile X-related protein and VIG associate with the RNA interference machinery. Genes Dev 16:2491-2496.

Chen L, Toth M (2001) Fragile X mice develop sensory hyperreactivity to auditory stimuli. Neuroscience 103:1043-1050.

El Idrissi A, Ding XH, Scalia J, Trenkner E, Brown WT, Dobkin C (2005) Decreased $\mathrm{GABA}_{\mathrm{A}}$ receptor expression in the seizure-prone fragile $\mathrm{X}$ mouse. Neurosci Lett 377:141-146.

Hou L, Klann E (2004) Activation of the phosphoinositide 3-kinase-Aktmammalian target of rapamycin signaling pathway is required for metabotropic glutamate receptor-dependent long-term depression. J Neurosci 24:6352-6361.

Huber KM, Kayser MS, Bear MF (2000) Role for rapid dendritic protein synthesis in hippocampal mGluR-dependent long-term depression. Science 288:1254-1257.

Huber KM, Gallagher SM, Warren ST, Bear MF (2002) Altered synaptic plasticity in a mouse model of fragile $\mathrm{X}$ mental retardation. Proc Natl Acad Sci USA 99:7746-7750.

Ishizuka A, Siomi MC, Siomi H (2002) A Drosophila fragile X protein interacts with components of RNAi and ribosomal proteins. Genes Dev 16:2497-2508.

Jin P, Alisch RS, Warren ST (2004) RNA and microRNAs in fragile X mental retardation. Nat Cell Biol 6:1048-1053.

Karachot L, Shirai Y, Vigot R, Yamamori T, Ito M (2001) Induction of longterm depression in cerebellar Purkinje cells requires a rapidly turned over protein. J Neurophysiol 86:280-289.

Kelleher III RJ, Govindarajan A, Tonegawa S (2004) Translational regulatory mechanisms in persistent forms of synaptic plasticity. Neuron 44:59-73.

Klann E, Dever TE (2004) Biochemical mechanisms for translational regulation in synaptic plasticity. Nat Rev Neurosci 5:931-942.

Lee AC, Wong RKS, Chuang SC, Shin HS, Bianchi R (2002) Role of synaptic metabotropic glutamate receptors in epileptiform discharges in hippocampal slices. J Neurophysiol 88:1625-1633.

Merlin LR, Wong RKS (1997) Role of group I metabotropic glutamate receptors in the patterning of epileptiform activities in vitro. J Neurophysiol 78:539-544.

Merlin LR, Bergold PJ, Wong RKS (1998) Requirement of protein synthesis for group I mGluR-mediated induction of epileptiform discharges. J Neurophysiol 80:989-993.

Musumeci SA, Hagerman RJ, Ferri R, Bosco P, Dalla Bernardina B, Tassinari CA, De Sarro GB, Elia M (1999) Epilepsy and EEG findings in males with fragile X syndrome. Epilepsia 40:1092-1099.

Musumeci SA, Bosco P, Calabrese G, Bakker C, De Sarro GB, Elia M, Ferri R, Oostra BA (2000) Audiogenic seizures susceptibility in transgenic mice with fragile X syndrome. Epilepsia 41:19-23.

Nakamura T, Barbara JG, Nakamura K, Ross WN (1999) Synergistic release of $\mathrm{Ca}^{2+}$ from $\mathrm{IP}_{3}$-sensitive stores evoked by synaptic activation of mGluRs paired with backpropagating action potentials. Neuron 24:727-737.

O’Donnell WT, Warren ST (2002) A decade of molecular studies of fragile X syndrome. Annu Rev Neurosci 25:315-338.

Qin M, Kang J, Burlin TV, Jiang C, Smith CB (2005) Postadolescent changes in regional cerebral protein synthesis: an in vivo study in the Fmr1 null mouse. J Neurosci 25:5087-5095.

Raymond CR, Thompson VL, Tate WP, Abraham WC (2000) Metabotropic glutamate receptors trigger homosynaptic protein synthesis to prolong long-term potentiation. J Neurosci 20:969-976.

Sabaratnam M, Vroegop PG, Gangadharan SK (2001) Epilepsy and EEG findings in 18 males with fragile X syndrome. Seizure 10:60-63. 
Shin CY, Kundel M, Wells DG (2004) Rapid, activity-induced increase in tissue plasminogen activator is mediated by metabotropic glutamate receptor-dependent mRNA translation. J Neurosci 24:9425-9433.

Steward O, Schuman EM (2003) Compartmentalized synthesis and degradation of proteins in neurons. Neuron 40:347-359.

Taylor GW, Merlin LR, Wong RKS (1995) Synchronized oscillations in hippocampal CA3 neurons induced by metabotropic glutamate receptor activation. J Neurosci 15:8039-8052.

Todd PK, Mack KJ, Malter JS (2003) The fragile X mental retardation protein is required for type-I metabotropic glutamate receptor-dependent translation of PSD-95. Proc Natl Acad Sci USA 100:14374-14378.

Weiler IJ, Irwin SA, Klintsova AY, Spencer CM, Brazelton AD, Miyashiro K, Comery TA, Patel B, Eberwine J, Greenough WT (1997) Fragile X mental retardation protein is translated near synapses in response to neurotransmitter activation. Proc Natl Acad Sci USA 94:53955400 .

Wong RKS, Chuang SC, Bianchi R (2004) Plasticity mechanisms underlying mGluR-induced epileptogenesis. Adv Exp Med Biol 548:69-75.

Yan QJ, Asafo-Adjei PK, Arnold HM, Brown RE, Bauchwitz RP (2004) A phenotypic and molecular characterization of the fmr1-tm1Cgr fragile X mouse. Genes Brain Behav 3:337-359.

Yan QJ, Rammal M, Tranfaglia M, Bauchwitz RP (2005) Suppression of two major fragile X syndrome mouse model phenotypes by the mGluR5 antagonist MPEP. Neuropharmacology, in press.

Zhao W, Bianchi R, Wang M, Wong RKS (2004) Extracellular signalregulated kinase $1 / 2$ is required for the induction of group I metabotropic glutamate receptor-mediated epileptiform discharges. J Neurosci $24: 76-84$. 